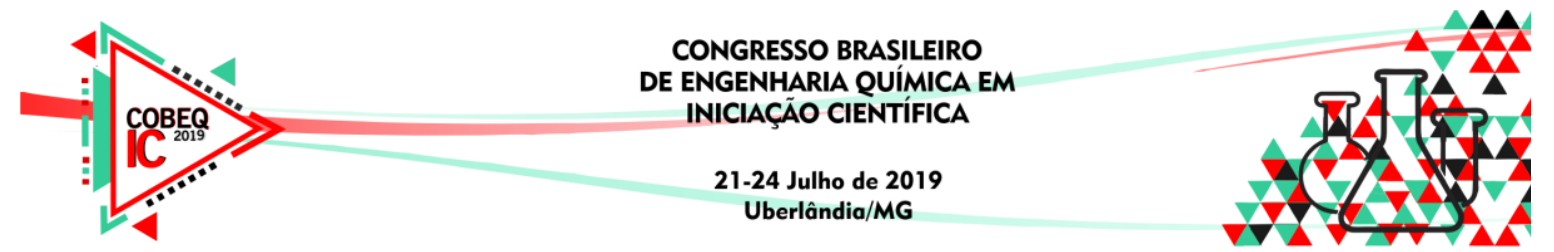

\title{
METALS RECOVERY FROM A SYNTHETIC EFFLUENT BASED ON THE PRESSURE OXIDATION STAGE VIA ION EXCHANGE RESIN
}

\author{
Y. A. R. LEBRON ${ }^{1}$, V. R. MOREIRA ${ }^{1}$, A. F. S. FOUREAUX ${ }^{2}$, L. V. S. SANTOS ${ }^{1,2}$, M. C. \\ S. AMARAL ${ }^{2}$ \\ ${ }^{1}$ Pontifical Catholic University of Minas Gerais, Department of Chemical Engineering \\ ${ }^{2}$ Federal University of Minas Gerais, Sanitary and Environmental Engineering Department \\ Contact E-mail: yuri.lebron@outlook.com
}

\begin{abstract}
The pressure oxidation process (POX) is frequently employed as a pre-oxidation step for refractory gold ores. This stage is responsible for the generation of a large volume of liquid effluents. Those are characterized by its high acidity and substantial metal content. Thus, in this study a cationic resin was employed, in different concentrations, to recover metals from a synthetic effluent. High correlation coefficients were found for the relationship between resin concentration and metal removal efficiency $\left(\mathrm{R}^{2}>89\right)$. Higher removal efficiency was observed for aluminum (97\%), followed by manganese $(91.7 \%)$, calcium $(85.7 \%)$, nickel $(83.8 \%)$, iron (83.7\%), copper $(82.7 \%)$ and manganese $(82.6 \%)$. Showing that the cation exchange resin was able to recover high concentrations of metals in a complex medium.
\end{abstract}

\section{INTRODUCTION}

An important step in the gold ores processing is pre-oxidation stage (POX). This process is used to alter or destroy the sulfide matrix and to make the gold accessible to the extraction process. Such ores are classified as refractory when at least $80 \%$ of the gold cannot be extracted by direct cyanidation even after fine grinding (Ricci et al., 2017). Normally, effluents resulting from ore processing contain hazardous substances such as heavy metals, metalloids, acids and process chemicals. To address their treatment, different methods can be employed, such as neutralization, ion-exchange (IX), electrochemical and membrane separation processes (Amaral et al., 2018). The IX process, which was first described in 1850 as occurring naturally in aluminosilicates minerals, such as clays, ultramarines and aerolites, emerges as an alternative to the conventional forms employed, being a consolidated technology of great industrial applicability (Hubicki \& Kołodyńska, 2012). In this study a cationic resin was employed, in different concentrations, to recover metals from a synthetic effluent.

\section{MATERIALS AND METHODS}

\subsection{Synthetic wastewater preparation}

A synthetic POX wastewater was prepared based on different compositions reported in the literature by dissolving specific amounts of salts in ultrapure water (MilliQ). The $\mathrm{pH}$ was 


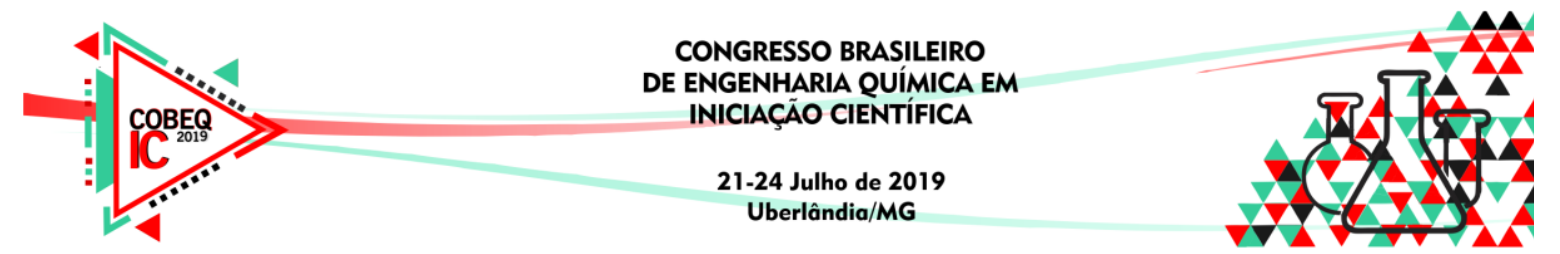

adjusted by analytical grade sulfuric acid $\left(\mathrm{H}_{2} \mathrm{SO}_{4}\right)$ and the synthetic wastewater final physicalchemical properties are presented in Table 1. All reagents used were analytical grade.

Table 1 - Synthetic effluent physicochemical properties

\begin{tabular}{|c|c|c|c|c|c|}
\hline Metal & Salt & $\begin{array}{c}\text { Concentration } \\
(\mathrm{mg} / \mathrm{L})\end{array}$ & $\begin{array}{c}\mathrm{SO}_{4}{ }^{2-} \\
\text { concentration } \\
(\mathrm{g} / \mathrm{L})\end{array}$ & pH & $\begin{array}{c}\text { Conductivity } \\
(\mathrm{mS} / \mathrm{cm})\end{array}$ \\
\hline $\mathrm{Fe}$ (II) & $\mathrm{FeSO}_{4} \cdot 7 \mathrm{H}_{2} \mathrm{O}$ & $990.45 \pm 10.58$ & \multirow{7}{*}{$5.17 \pm 1.02$} & \multirow{7}{*}{$1.51 \pm 0.01$} & \multirow{7}{*}{$33.7 \pm 1.0$} \\
\hline $\mathrm{Ca}$ (II) & $\mathrm{CaCl}_{2}$ & $141.15 \pm 3.22$ & & & \\
\hline $\mathrm{Al}$ (III) & $\mathrm{AlCl}_{3} \cdot 6 \mathrm{H}_{2} \mathrm{O}$ & $714.58 \pm 18.53$ & & & \\
\hline $\mathrm{Cu}$ (II) & $\mathrm{CuSO}_{4} \cdot 5 \mathrm{H}_{2} \mathrm{O}$ & $102.22 \pm 0.43$ & & & \\
\hline $\mathrm{Mg}$ (II) & $\mathrm{MgSO}_{4} \cdot 7 \mathrm{H}_{2} \mathrm{O}$ & $595.61 \pm 11.50$ & & & \\
\hline $\mathrm{Ni}$ (II) & $\mathrm{NiSO}_{4} \cdot 6 \mathrm{H}_{2} \mathrm{O}$ & $201.50 \pm 3.29$ & & & \\
\hline $\mathrm{Mn}$ (II) & $\mathrm{MnSO}_{4} \cdot \mathrm{H}_{2} \mathrm{O}$ & $19.99 \pm 1.95$ & & & \\
\hline
\end{tabular}

\subsection{Ion exchange experiments}

The IX tests were carried out in $125-\mathrm{mL}$ erlenmeyer flasks, containing $100 \mathrm{~mL}$ of synthetic wastewater and different resin concentrations $(100-300 \mathrm{~g} / \mathrm{L})$. In the tests a strong cation exchanger resin (Amberlite IRA 120) was used with an average particle size of 570 $670 \mu \mathrm{m}$ and a total volume capacity $(\mathrm{Na})$ of $2.00 \mathrm{eq} / \mathrm{L}$. The system was kept under constant agitation $(400 \mathrm{rpm})$ and temperature $\left(28^{\circ} \mathrm{C}\right)$ in a shaker (Marconi MA420) for 12 hours, enough time to ensure the equilibrium was achieved. Then, aliquots were collected from the system to determine the resin adsorption capacity (Equation 1) and removal percentage (Equation 2). The initial and equilibrium concentration was determined by an atomic absorption spectrophotometer (Shimadzu AA-7000) with the aid of an external calibration curve $\left(R^{2}>\right.$ 0.99). In this method, method quantification limit was defined as the lowest point in the calibration curve $(0.1 \mathrm{mg} / \mathrm{L})$.

$$
\begin{aligned}
& q_{e}=v\left(C_{0}-C_{e}\right) / m \\
& \text { Removal }=\left(C_{0}-C_{e}\right) / C_{0}
\end{aligned}
$$

Where $q_{e}(\mathrm{mg} / \mathrm{g})$ corresponds to the resin adsorption capacity, $v(\mathrm{~L})$ to the volume of synthetic wastewater treated, $m(\mathrm{~g})$ to the resin mass, and $C_{0}(\mathrm{mg} / \mathrm{L})$ and $C_{e}(\mathrm{mg} / \mathrm{L})$ to the initial and equilibrium concentration, respectively.

\section{RESULTS AND DISCUSSION}

Higher removal efficiencies were observed for aluminum and manganese, justified by the higher driving force involving both ions (Table 2). 


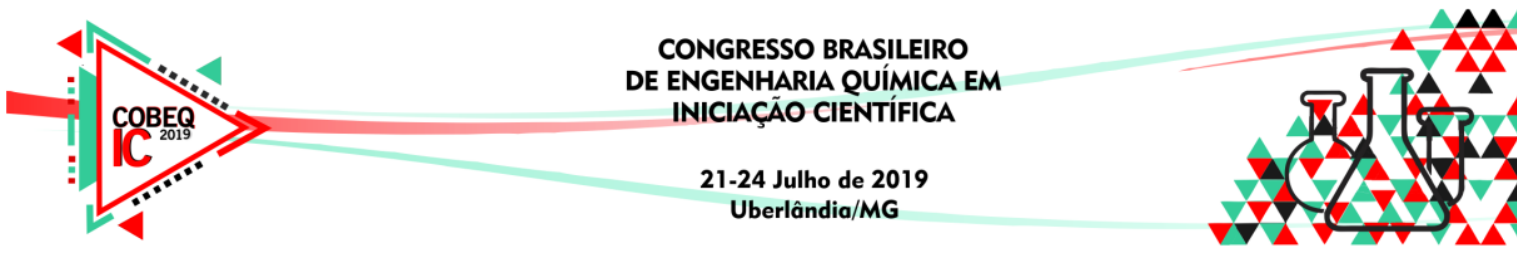

Table 2 - Experimental removal efficiency and correlation coefficients for different resin loads.

\begin{tabular}{|c|c|c|c|c|c|c|}
\hline \multirow{2}{*}{ Metal } & \multicolumn{3}{|c|}{ Resin concentration (g/L) } & \multirow{2}{*}{ Angular } & \multirow{2}{*}{ Linear } & \multirow{2}{*}{$\mathbf{R}^{\mathbf{2}}$} \\
\cline { 2 - 7 } & $\mathbf{1 0 0}$ & $\mathbf{2 0 0}$ & $\mathbf{3 0 0}$ & & & \\
\hline \hline $\mathrm{Fe}$ (II) & $64.55 \%$ & $90.63 \%$ & $95.94 \%$ & 556.1 & -265.5 & 0.873 \\
\hline $\mathrm{Ca}$ (II) & $67.81 \%$ & $91.92 \%$ & $97.34 \%$ & 597.6 & -312.1 & 0.882 \\
\hline $\mathrm{Al}$ (III) & $92.20 \%$ & $99.05 \%$ & $99.73 \%$ & 2170.8 & -1905.6 & 0.817 \\
\hline $\mathrm{Cu}$ (II) & $61.88 \%$ & $89.83 \%$ & $96.51 \%$ & 512.9 & -224.4 & 0.888 \\
\hline $\mathrm{Mg}$ (II) & $62.31 \%$ & $90.26 \%$ & $95.27 \%$ & 522.4 & -231.5 & 0.861 \\
\hline $\mathrm{Ni}$ (II) & $64.43 \%$ & $90.84 \%$ & $96.00 \%$ & 550.3 & -260.9 & 0.869 \\
\hline $\mathrm{Mn}$ (II) & $76.92 \%$ & $98.20 \%$ & $>99.75 \%$ & 700.0 & -441.9 & 0.808 \\
\hline
\end{tabular}

Furthermore, reasonable correlation coefficients for the linear fit, between the resin concentration (y) and the removal efficiency (x), were observed (Table 2). The angular coefficient can be used to determine which metal is most sensitive to resin concentration in the medium. Among the largest angular coefficients are aluminum, followed by manganese and calcium, indicating that a small increase in resin concentration in the medium causes a great increase in the removal efficiency of these metals from the medium. Figure 2 shows that the removal increases with increasing amounts of resin regardless of the metal and its initial concentration. Higher removal percentages were observed for aluminum, followed by manganese, calcium, nickel, iron, copper and manganese. For the medium containing $300 \mathrm{~g} / \mathrm{L}$ of resin the final concentrations varied between $0.22-3.16 \mathrm{mg} / \mathrm{L}$, reaching the limits set by the Brazilian National Environmental Council (CONAMA) through ordinance 430 in terms of metal concentrations. Of the metals that constitute the POX effluent, the organ imposes discharge limits for iron $(15 \mathrm{mg} / \mathrm{L})$, copper $(1 \mathrm{mg} / \mathrm{L})$, nickel $(2 \mathrm{mg} / \mathrm{L})$ and manganese $(1.0$ $\mathrm{mg} / \mathrm{L})$

Figure 2 - Removal percentage and metal average extraction for different resin amounts.

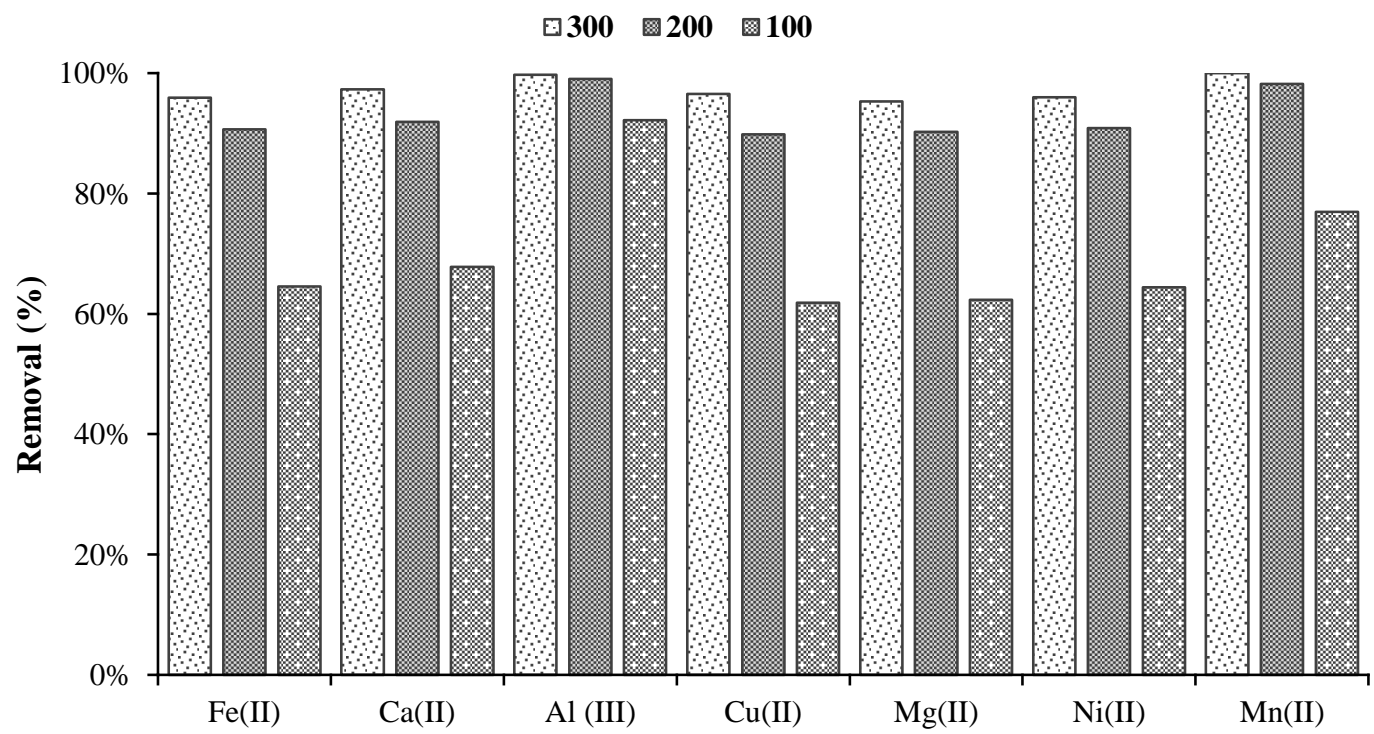




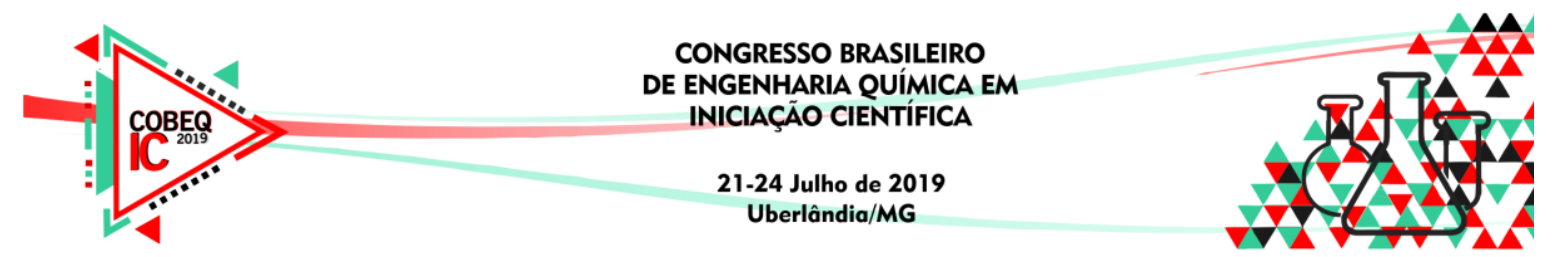

Figure 3 - Final concentrations for the medium containing $300 \mathrm{~g} / \mathrm{L}$ of resin.

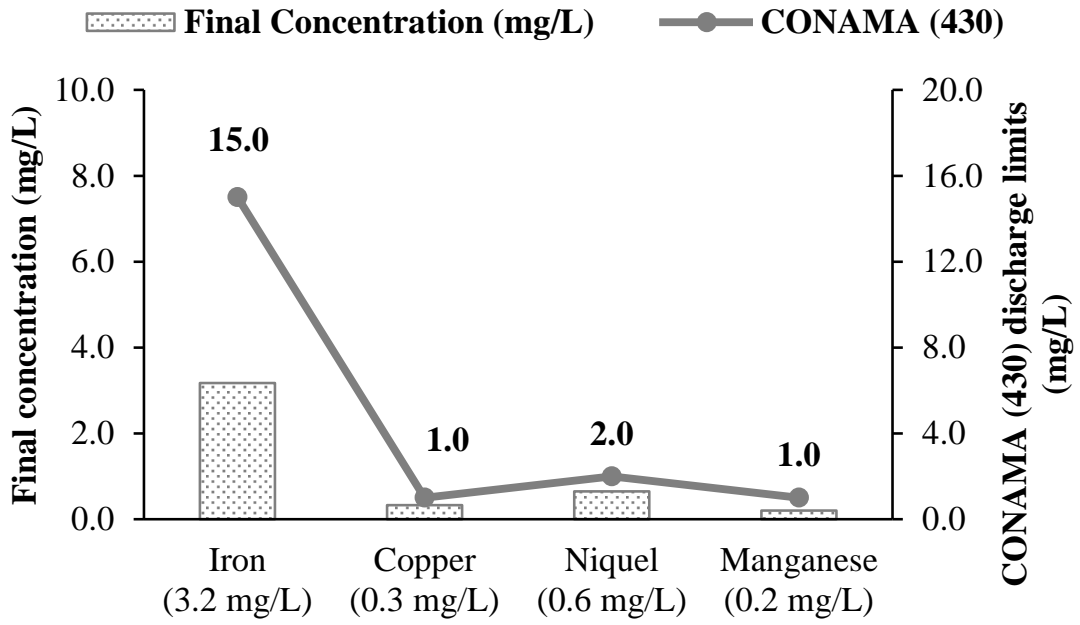

\section{CONCLUSIONS}

The ion exchange process presents itself as an alternative to the treatment of the effluent generated in the gold mining industry. These effluents present high metal and acid concentrations, possible value-added compounds that could be recovered. From the experimental conditions employed, removals between 82.8 and $97.0 \%$ were achieved, in accordance with the discharge standards established by the National Council for the Environment for the metals content. Moreover, high correlation coefficients were observed between the resin concentration and the removal efficiency, in which aluminum presented the highest sensitivity to resin concentration in the medium.

\section{REFERENCES}

CONAMA, Conselho Nacional de Meio Ambiente. Resolução No 430.

RICCI, Bárbara C. et al. Assessment of the chemical stability of nanofiltration and reverse osmosis membranes employed in treatment of acid gold mining effluent. Separation and Purification Technology, v. 174, p. 301-311, 2017.

AMARAL, Míriam C.S. et al. Integrated UF-NF-RO route for gold mining effluent treatment: From bench-scale to pilot-scale. Desalination, v. 440, p. 111-121, 2018.

HUBICKI, Zbigniew; KOŁODYŃSKA, Dorota. Selective removal of heavy metal ions from waters and waste waters using ion exchange methods. In: Ion Exchange Technologies. IntechOpen, 2012. 